\title{
Rostral Ventromedial Medulla Neurons That Project to the Spinal Cord Express Multiple Opioid Receptor Phenotypes
}

\author{
Silvia Marinelli, ${ }^{1}$ Christopher W. Vaughan, ${ }^{1,2}$ Stephen A. Schnell, ${ }^{3}$ Martin W. Wessendorf, ${ }^{3}$ and \\ MacDonald J. Christie ${ }^{1}$ \\ ${ }^{1}$ Department of Pharmacology and The Medical Foundation, The University of Sydney, Sydney, New South Wales 2006 \\ Australia, ${ }^{2}$ Department of Anaesthesia and Pain Management, Royal North Shore Hospital New South Wales, New South \\ Wales 2065 Australia, and ${ }^{3}$ Department of Neuroscience, University of Minnesota, Minneapolis, Minnesota 55455
}

The rostral ventromedial medulla (RVM) forms part of a descending pathway that modulates nociceptive neurotransmission at the level of the spinal cord dorsal horn. However, the involvement of descending RVM systems in opioid analgesia are a matter of some debate. In the present study, patch-clamp recordings of RVM neurons were made from rats that had received retrograde tracer injections into the spinal cord. More than $90 \%$ of identified spinally projecting RVM neurons responded to opioid agonists. Of these neurons, 53\% responded only to the $\mu$-opioid agonist D-Ala2, N-Me-Phe4, Gly-ol5 enkephalin, $14 \%$ responded only to the $\kappa$-opioid agonist U-69593, and another group responded to both $\mu$ and $\kappa$ opioids (23\%). In unidentified RVM neurons, a larger proportion of neurons responded only to $\mu$ opioids (75\%), with smaller proportions of $\kappa^{-}$ (4\%) and $\mu / \kappa$-opioid (13\%) responders. These RVM slices were then immunostained for tryptophan hydroxylase (TPH), a marker of serotonergic neurons. Forty-percent of spinally projecting neurons and $11 \%$ of unidentified neurons were TPH positive. Of the TPH-positive spinally projecting neurons, there were similar proportions of $\mu$ - $(33 \%), \kappa^{-}(25 \%)$, and $\mu / \kappa_{\text {-opioid }}$ (33\%) responders. Most of the TPH-negative spinally projecting neurons were $\mu$-opioid responders (67\%). These findings indicate that functional opioid receptor subtypes exist on spinally projecting serotonergic and nonserotonergic RVM neurons. The proportions of $\mu$ - and $\kappa$-opioid receptors expressed differ between serotonergic and nonserotonergic neurons and between retrogradely labeled and unlabeled RVM neurons. We conclude that important roles exist for both serotonergic and nonserotonergic RVM neurons in the mediation of opioid effects.

Key words: rostral ventromedial medulla; spinal cord; opioid receptor; analgesia; serotonergic; patch clamp; immunohistochemistry
The rostral ventromedial medulla (RVM) is a crucial site for the supraspinal antinociceptive actions of opioids (Fields et al., 1991). The RVM, particularly the nucleus raphe magnus, forms a component of a descending inhibitory network that modulates nociceptive neurotransmission at the level of the spinal cord dorsal horn. Whole-animal electrophysiological experiments have identified three classes of neurons within the RVM, including ON-, OFF-, and NEUTRAL-cells that display, respectively, increases, decreases, and no changes in action potential activity associated with nociceptive tail-flick responses (Fields et al., 1988). Microinjection of antinociceptive doses of $\mu$ opioids into the RVM inhibits ON-cells and excites OFF-cells (Heinricher et al., 1992, 1994, 1999); microinjection of $\kappa$ opioids reduces the antinociceptive effect of $\mu$ agonists (Pan et al., 1997). In vitro electrophysiological experiments have identified secondary cells that are directly inhibited by $\mu$ opioids and primary cells that are directly inhibited by $\kappa$ opioids and receive $\mu$-opioid-sensitive GABAergic inputs (Pan et al., 1990, 1997; Ackley et al., 2001).

\footnotetext{
Received July 11, 2002; revised Sept. 23, 2002; accepted Sept. 30, 2002.

This work was supported by United States Public Health Service Grant DA09642, by Medical Research Council Australia Grants 211168 and 153844, and by The Medical Foundation of The University of Sydney.

Correspondence should be addressed to Prof. MacDonald J. Christie, Department of Pharmacology, University of Sydney, New South Wales, 2006, Australia. E-mail: macc@med.usyd.edu.au.

S. Marinelli's present address: Instituto di Recovera e Cura a Carattere Scientifico Fondazione Santa Lucia, 00179 Rome, Italy.

Copyright (C) 2002 Society for Neuroscience $0270-6474 / 02 / 2210847-09 \$ 15.00 / 0$
}

It has been proposed that $\mu$-opioid agonists activate a descending antinociceptive pathway originating within the RVM by reducing the inhibitory influence of GABAergic neurons (disinhibition) onto bulbospinal neurons (Fields et al., 1991; Fields and Basbaum, 1999; Heinricher et al., 1999). This hypothesis suggests that the $\mu$-opioid-responsive secondary cells (which appear similar to ON-cells in vivo) are pronociceptive GABAergic neurons and the $\kappa$-opioid-responsive primary cells (which appear similar to OFF-cells) are antinociceptive spinal projection neurons (Pan et al., 1997). At least some ON- and OFF-cells project to the spinal cord (Vanegas et al., 1984) and dorsal horn (Fields et al., 1995); however, to date, the projections of primary and secondary cells have not been studied.

Although many spinally projecting RVM neurons are serotonergic, their role in antinociception is controversial (Christie, 1998; Huang, 1998; Mason and Gao, 1998; Wessendorf, 1998). Functional studies have demonstrated that intra-RVM morphineinduced analgesia is blocked by systemic serotonergic antagonists and that RVM stimulation-induced analgesia is blocked by intrathecal serotonergic antagonists (Azami et al., 1982; Hammond and Yaksh, 1984; Yaksh et al., 1988). In addition, primary, but not secondary, cells recorded in vitro are reported to be serotonergic on the basis of immunohistochemistry and action potential shape (Pan et al., 1990, 1993). However, most serotonergic RVM cells recorded in vivo are not ON- or OFF-cells (Potrebic et al., 1994), and do not respond to periaqueductal gray matter stimulation or morphine (Gao et al., 1997; 1998). In addition, it has been reported that spinally projecting serotonergic RVM neurons ex- 
press both $\mu$ - and $\kappa$-opioid receptors (Kalyuzhny et al., 1996; Kalyuzhny and Wessendorf, 1999).

In the present study, we have used a combination of in vitro electrophysiological and anatomical techniques to characterize the opioid responses and neurochemical identity of RVM neurons that project to the spinal cord. We find that the responses to opioids of both serotonergic and nonserotonergic neurons are consistent with our previous anatomical findings.

\section{MATERIALS AND METHODS}

Injections of retrograde tracer. Microinjection of rhodamine-conjugated latex microspheres (Molecular Probes, Eugene, OR) into the spinal cord dorsal horn was performed in 8- to 11-d-old male Sprague Dawley rats. The animals were anesthetized (1-2\% halothane vaporized in $100 \% \mathrm{O}_{2}$ ), and the spinal cord was exposed by performing a laminectomy over one lumbar segment (between L3 and L5). The dura was cut, and a glass micropipette (tip diameter $20-50 \mu \mathrm{m}$ ) was advanced into the dorsal horn of the spinal cord at an angle of $45^{\circ}$ to the rostrocaudal axis. Between two and four injections (10 $\mathrm{nl}$ each) were made bilaterally using a calibrated injection system (Drummond Nanoject, Broomall, PA). The incision was then closed, and a topical antibiotic was applied. Animals were allowed to recover from anesthesia in a warmed box before being returned to holding cages with their mother and litter. Between 2 and $5 \mathrm{~d}$ after surgery, animals were used for in vitro experiments. The spinal cord was fixed, and coronal sections were cut to verify the location of the injection sites (see Fig. 1).

Brain slice preparation and recordings. Sprague Dawley rats, 10-18 $\mathrm{d}$ old, with and without previous spinal cord tracer injections, were anesthetized with halothane and decapitated. Four to five coronal brain slices $(250 \mu \mathrm{m}$ thick) were cut beginning at the level of the rostral end of the fourth ventricle and proceeding caudally. The slices were cut in ice-cold artificial CSF (ACSF) of the following composition (in mM): $126 \mathrm{NaCl}, 2.5 \mathrm{KCl}, 1.4 \mathrm{NaH}_{2} \mathrm{PO} 4,1.2 \mathrm{MgCl}_{2}$, $2.4 \mathrm{CaCl}_{2}, 11$ glucose, $25 \mathrm{NaHCO}_{3}$. Slices were maintained at $34^{\circ} \mathrm{C}$ in a submerged chamber containing ACSF equilibrated with a mixture of $5 \% \mathrm{CO}_{2}$ and $95 \% \mathrm{O}_{2}$. The brain slices were then transferred to a chamber and superfused continuously $(2 \mathrm{ml} / \mathrm{min})$ with ACSF $\left(34^{\circ} \mathrm{C}\right)$.

Recordings were made from RVM neurons in three types of experiments: (1) those in which we recorded retrogradely labeled neurons that were identified (under fluorescence illumination) by the presence of fluorescent microspheres in their cell bodies, (2) those in which we recorded randomly selected neurons from animals that had received spinal cord tracer injections, and (3) those in which we recorded randomly selected neurons from animals that had not received spinal cord tracer injections. In all experiments, RVM neurons were visualized in the triangular midline region dorsal to the pyramidal tracts using infrared Nomarski optics on an upright microscope (Olympus BX50). Whole-cell patch-clamp recordings of transmembrane currents (holding potential $-60 \mathrm{mV}$ ) were performed using patch electrodes (2-5 M $\Omega$ ) filled with an internal solution containing (in mM): $115 \mathrm{~K}$-gluconate, $25 \mathrm{KCl}, 15 \mathrm{NaCl}, 1$ $\mathrm{MgCl}_{2}, 10$ HEPES, 11 EGTA, $2 \mathrm{MgATP}, 0.25 \mathrm{NaGTP}$, and $0.01 \%$ biocytin, $\mathrm{pH} 7.3$, osmolarity $280-285 \mathrm{mOsm} / 1$. Series resistance $(<$ $15 \mathrm{M} \Omega$ ) was compensated by $80 \%$ and monitored continuously during experiments with an Axopatch 1D amplifier (Axon Instruments, Foster City, CA). Liquid junction potentials of $-10 \mathrm{mV}$ were corrected. Postsynaptic currents were filtered (50 Hz low-pass filter) and sampled $(100 \mathrm{~Hz})$ for later analysis (Axograph 4, Axon Instruments). All numerical data are expressed as means \pm SEM, and statistical comparisons were made using $\chi^{2}$ tests for differences among proportions.

Immunohistochemistry. Recordings lasted $20 \mathrm{~min}$, at most. Immediately after, slices containing biocytin-filled cells were fixed for 30 min in a phosphate-buffered paraformaldehyde/picric acid solution [75 mM KH $\mathrm{PO}_{4}, 85 \mathrm{~mm} \mathrm{Na} \mathrm{HPO}_{4}, 4 \%$ (w/v) paraformaldehyde, $14 \%$ (v/v) saturated aqueous picric acid, $\mathrm{pH}$ 6.9]. The slices were then washed six to eight times and stored in a phosphate-buffered sucrose solution [30 mM KH $\mathrm{KO}_{4}, 70 \mathrm{~mm} \mathrm{Na} \mathrm{HPO}_{4}, 10 \%$ sucrose (w/v), $0.01 \%(\mathrm{w} / \mathrm{v})$ sodium azide, $0.032 \%(\mathrm{w} / \mathrm{v})$ bacitracin, $\mathrm{pH} 7.2]$. Brainstem slices and spinal cords were shipped by courier from Sydney to Minneapolis for the anatomical portion of the experiments. Biocytin-filled cells were visualized by incubation with Cy5labeled streptavidin (Jackson ImmunoResearch, West Grove, PA). Tryptophan hydroxylase immunoreactivity (TPH-ir) was visualized using a sheep anti-TPH antiserum (Chemicon, Temecula, CA) followed by Cy2-conjugated donkey anti-sheep IgG (Jackson ImmunoResearch). Because fluorescent microspheres can be dissolved by xylene-based mounting media, slices were mounted with coverslips using $85 \%(\mathrm{w} / \mathrm{v})$ aqueous sucrose. Images of filled cells were collected using an MRC 1000 or MRC 1024 confocal microscope (Bio-Rad, Hercules, CA), and we identified the brainstem level at which filled cells occurred by reference to the pontine gray matter, the trapezoid body/superior olivary complex, and the facial nucleus. Spinal cord segments were sectioned at a nominal thickness of 100 $\mu \mathrm{m}$ using a freezing microtome. Spinal sites at which the fluorescent microspheres were injected were examined using conventional fluorescence microscopy, and reconstructions of the extents of injection sites were made from digital images.

Drugs, reagents, and solutions. All stock solutions for in vitro experiments were made in distilled water except for U-69593, which was made in $0.1 \% \mathrm{HCl}$. These solutions were diluted at working concentrations in the extracellular solution immediately before use and applied by superfusion. D-Ala2, $\mathrm{N}$-Me-Phe4, Gly-ol5 enkephalin (DAMGO), methionine-enkephalin (met-enkephalin), and Phe-GlyGly-Phe-Thr-Gly-Ala-Arg-Lys-Ser-Ala-Arg-Lys-Leu-Ala-Asn-Gln (nociceptin) were obtained from Auspep (Melbourne, Australia). Nor-binaltorphimine dihydrochloride (nor-BNI) and U-69593 were from Research Biochemicals (Natick, MA). 5-Hydroxytryptamine and biocytin were from Sigma (Sydney, Australia). D-Phe-Cys-TyrD-Trp-Arg-Pen-Thr-NH $\mathrm{N}_{2}$ (CTAP) was from Phoenix Pharmaceuticals (Mountain View, CA).

\section{RESULTS}

\section{Opioid responses of spinally projecting RVM neurons}

We first characterized the opioid responses of RVM neurons that were identified as projecting to the spinal cord. After injection of the fluorescent microspheres into the spinal cord, many neurons in the RVM were observed to contain retrograde tracer. Wholecell voltage-clamp recordings (holding potential $-60 \mathrm{mV}$ ) were made from 73 retrogradely labeled neurons throughout the RVM with varying cell size and morphology. Post hoc imaging of the biocytin-filled neurons confirmed the presence of fluorescent microspheres within the recorded neurons (Fig. 1).

Four types of spinally projecting RVM neurons were identified on the basis of their membrane current responses to $\mu$ - and $\kappa$-opioid receptor activation. The first group of spinally projecting RVM neurons responded only to $\mu$-opioid receptor activation (Fig. 2a). In these neurons, superfusion of the selective $\mu$-opioid agonist DAMGO (1-3 $\mu \mathrm{M})$ produced a reversible outward current ( $38 \pm 6 \mathrm{pA} ; n=25)$, whereas the $\kappa$-opioid agonist $\mathrm{U}-69593$ (1-3 $\mu \mathrm{M})$ was without effect $(n=39)$. The DAMGO-induced current was reversed by addition of the $\mu$-opioid antagonist CTAP (300 nм-1 $\mu \mathrm{M} ; n=15)$. The endogenous opioid ligand met-enkephalin $(10 \mu \mathrm{M})$ also produced an outward current in these neurons $(41 \pm 3 \mathrm{pA} ; n=31)$. The second group of spinally projecting RVM neurons responded only to $\kappa$-opioid receptor 

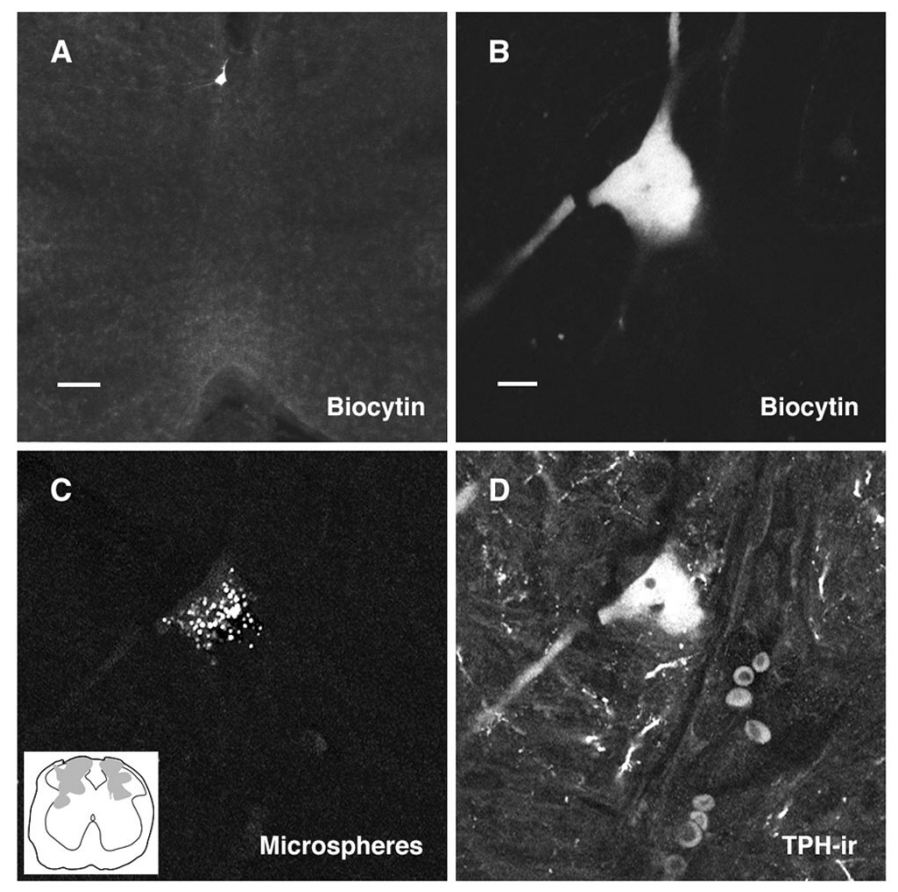

Figure 1. Electrophysiologically characterized serotonergic RVM cell that was retrogradely labeled from the dorsal spinal cord. This cell responded to both $\mu$ - and $\kappa$-opioid receptors. $A$, Low-magnification image of the cell on the midline of the brainstem, $\sim 600 \mu \mathrm{m}$ dorsal to the pyramidal tract. $B$, High-magnification image of the biocytin-filled cell. $C$, High-magnification image of the fluorescent microspheres present within the cell. Inset, Extent in the coronal plane of the spinal injection site of the fluorescent microspheres. $D$, High-magnification image of TPH-ir in the biocytin-filled cell. The high-magnification images were all collected at the same optical plane using confocal microscopy. Scale bars: $A, 100 \mu \mathrm{m}$; $B-D, 10 \mu \mathrm{m}$.

activation (Fig. $2 b$ ). In these neurons, U-69593 (300 nм-1 $\mu \mathrm{M})$ produced an outward current $(65 \pm 15 \mathrm{pA})$ that was reversed by the $\kappa$-opioid antagonist nor-BNI (300 nM-1 $\mu \mathrm{M})$, whereas DAMGO $(1-3 \mu \mathrm{M})$ produced no change in membrane current $(n=10)$. The third group of spinally projecting RVM neurons responded to both $\mu$ - and $\kappa$-opioid receptor activation (Fig. $2 c$ ). In these neurons, U-69593 (300 nM-3 $\mu \mathrm{M})$ produced an outward current (35 $\pm 7 \mathrm{pA} ; n=17)$, which was reversed by nor-BNI (1 $\mu \mathrm{M} ; n=13)$. In addition, DAMGO $(1-3 \mu \mathrm{M} ; 32 \pm 7 \mathrm{pA} ; n=13)$ and/or met-enkephalin (10 $\mu \mathrm{M} ; 48 \pm 10 \mathrm{pA} ; n=14)$ produced an outward current. The fourth group of spinally projecting RVM neurons did not respond to $\mu$ - or $\kappa$-opioid agonists $(n=7$; data not shown). However, subsequent application of 5-hydroxytryptamine ( $3 \mu \mathrm{M} ; 47 \pm 10 \mathrm{pA} ; n=3)$ or nociceptin (300 nM; $88 \pm$ $29 \mathrm{pA} ; n=4)$ produced an outward current, confirming that these neurons were responsive to activation of other $G_{i / o}$-proteincoupled receptors.

The proportions of these three opioid responsive types differed (Fig. 3). The majority of spinally projecting neurons responded only to $\mu$-opioid receptor activation ( $53 \% ; n=39$ of 73$)$. Smaller proportions of projection neurons responded either only to $\kappa$-opioid receptor activation $(14 \% ; n=10$ of 73$)$ or to both $\mu$ - and $\kappa$-opioid receptor activation $(23 \% ; n=17$ of 73 ). The other neurons did not respond to either $\mu$ - or $\kappa$-opioid receptor activation $(10 \% ; n=7$ of 73$)$.
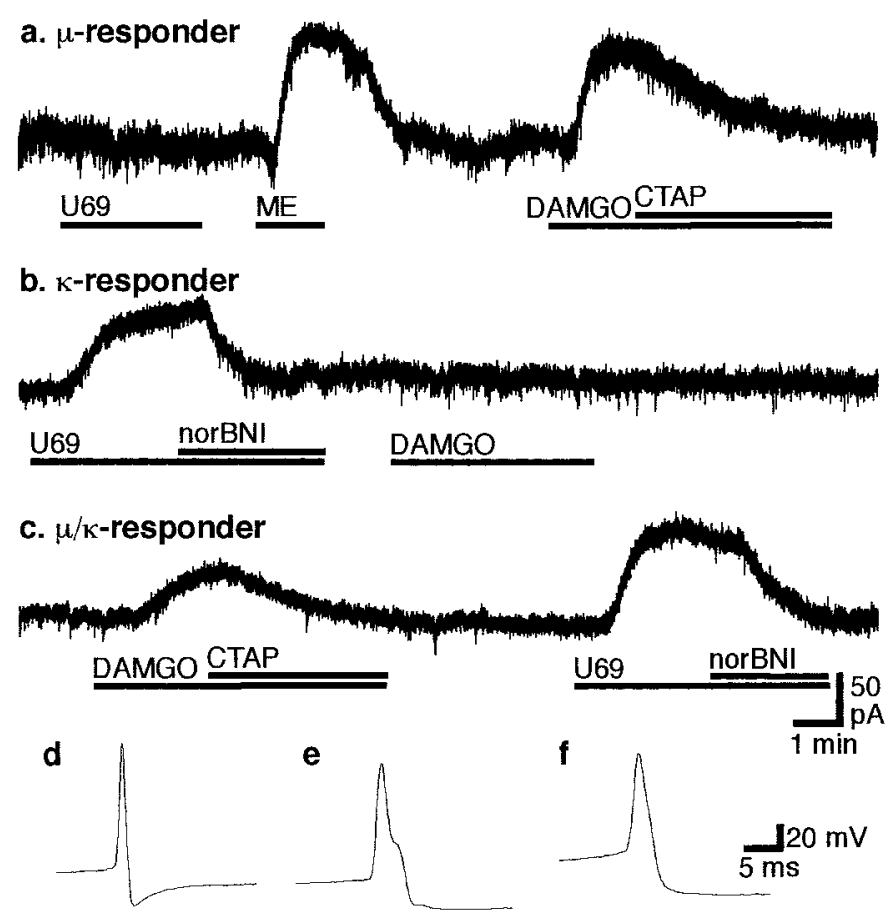

Figure 2. Three distinct categories of opioid-responding bulbospinal cells in RVM. Typical current traces of $\mu-(a), \kappa^{-}(b)$, and $\mu / \kappa^{-}(c)$ opioid-responding RVM neurons. The membrane current was recorded in RVM neurons during the superfusion of the opioid agonists U69593 (U69) $(1 \mu \mathrm{M})$, DAMGO $(3 \mu \mathrm{M})$, and met-enkephalin $(M E)(10 \mu \mathrm{M})$. The effects of DAMGO and U69593 were reversed by the $\mu$ - and $\kappa$-opioidselective antagonists CTAP $(1 \mu \mathrm{M})$ and nor-BNI (300 nM). Current traces $a-c$ are from different neurons that were voltage clamped at $-60 \mathrm{mV}$. The action potential traces for $d-f$ are from different neurons in current-clamp mode that are typical of the opioid-responding types in $a-c$, respectively.

In some experiments the shapes of action potentials were studied in current-clamp mode. We found that opioid-responsive neurons had distinctive action potential shapes (Fig. $2 d-f$ ). The majority of $\mu$-responsive neurons had short-duration action potentials (width at half-amplitude $=0.9 \pm 0.1 \mathrm{msec} ; n=36$ of 39). The majority of $\kappa$-opioid responsive neurons had long-duration action potentials (width at half-amplitude $=2.2 \pm 0.6 \mathrm{msec} ; n=$ 7 of 9$)$. The majority of $\mu / \kappa$-responsive neurons had shortduration action potentials (width at half-amplitude $=1.1 \pm 0.1$ msec; $n=7$ of 8 ).

Examination of the spinal cords of pups that had received injections of fluorescent microspheres showed that in all cases injections of microspheres were made into the dorsal horn of the spinal cord. In no cases were the injections restricted entirely to the dorsal horn, and they generally extended into the intermediate gray and sometimes the ventral horn. In 5 of 17 animals, injection sites were more restricted to the dorsal horn with additional labeling extending only into small portions of the intermediate gray immediately adjacent to the base of the dorsal horn. The proportion of $\mu, \kappa$, and $\mu / \kappa$ responders in the five animals with more restricted injected sites $(42,25$, and $25 \%$; $n=12)$ was similar to that observed in the 12 animals with larger injection sites that spread into the intermediate gray and the ventral horn $(55,18$, and $18 \% ; n=38)\left(p=0.7 ; \chi^{2}=0.7 ; \mathrm{df}=2\right)$. 


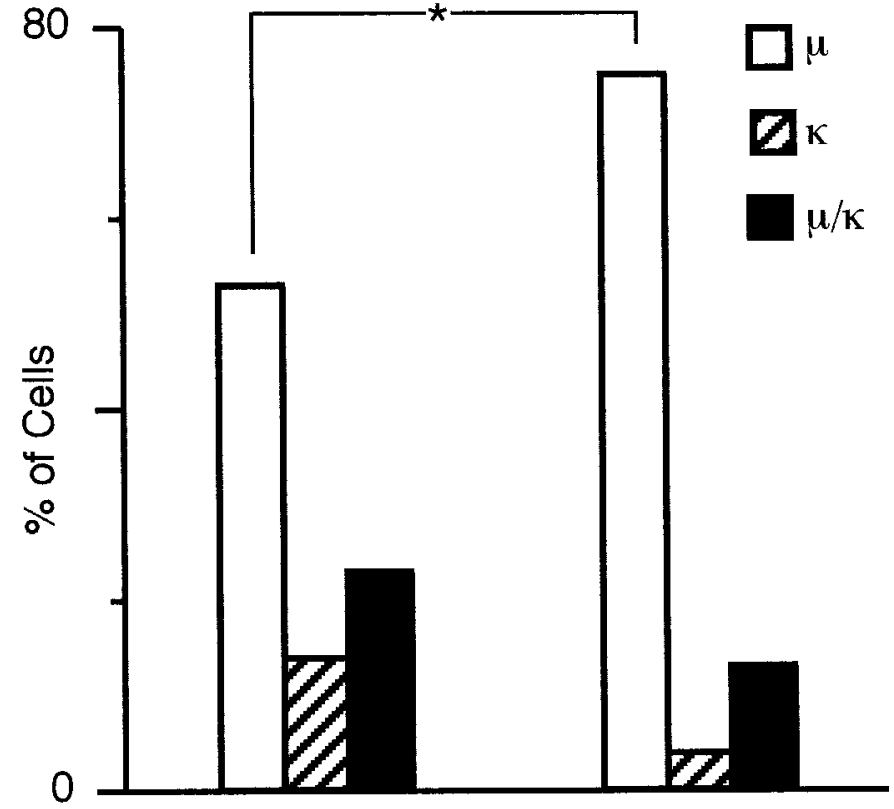

\section{Retro-labelled Random}

Figure 3. The proportion of opioid-responding subtypes differs between spinally projecting and randomly selected RVM neurons. Bar charts display the percentage of $\mu-, \kappa^{-}, \mu / \kappa$-opioid-responding neurons in recordings from retrogradely labeled neurons using fluorescence illumination (Retro-labelled) and from randomly sampled neurons with the fluorescence illumination off (Random). Both groups of neurons are from animals that had received previous spinal injections of fluorescent microspheres. ${ }^{*} p<0.05$.

\section{Opioid responses of RVM neurons not identified as projecting to the spinal cord}

We then attempted to characterize the opioid responses of RVM neurons that did not project to the spinal cord by recording from randomly selected RVM neurons. Whole-cell voltage-clamp recordings were made from 52 randomly selected RVM neurons (without first establishing whether they were retrogradely labeled) from animals that had received lumbar spinal cord tracer injections ( $n=14$ animals). As observed in the above experiments, we found four types of opioid-responsive neurons in the RVM (Fig. 3). The majority of these neurons responded only to $\mu$-opioid receptor activation (75\%; $n=39$ of 52). Smaller proportions of neurons responded only to $\kappa$ opioids ( $4 \% ; n=2$ of 52 ) or to both $\mu$ and $\kappa$ opioids ( $13 \% ; n=7$ of 52$)$, or did not respond to $\mu$ or $\kappa$ opioids $(8 \% ; n=4$ of 52$)$. Of the neurons that responded to opioids, those that were sampled randomly from spinally injected rats differed from those obtained when recordings were limited to spinally projecting neurons $\left(p<0.05 ; \chi^{2}=\right.$ 6.8 ; $\mathrm{df}=2$ ). In particular, the proportion of $\mu$-opioid-responsive neurons was higher in recordings from randomly selected neurons $\left(p<0.05 ; \chi^{2}=6.0 ; \mathrm{df}=1\right)$.

After recording opioid responses we then examined whether the randomly selected neurons projected to the spinal cord. Most of these neurons appeared not to contain fluorescent microspheres in their cell bodies ( $85 \% ; n=44$ of 52$)$, and most of the cells without microspheres responded only to $\mu$ opioids (82\%; $n=36$ of 44). As such, most of the cells described above as responding only to $\mu$ opioids were not retrogradely labeled (92\%; $n=36$ of 39). The other unlabeled RVM neurons were $\kappa$ responsive $(2 \% ; n=1$ of 44$)$ or $\mu / \kappa$ responsive (7\%; 3 of 44$)$, or did not respond to any opioid agonists $(9 \% ; n=4$ of 44$)$.

To control for any influence of the retrograde tracing procedures on opioid responsiveness, we then recorded randomly selected RVM neurons from animals that had not received spinal cord tracer injections. In these experiments, 46 biocytin-filled neurons were recovered that had been characterized for their opioid responses. Of these, $70 \%(n=32$ of 46$)$ were $\mu$ responsive, $13 \%(n=6$ of 46$)$ were $\kappa$ responsive, $13 \%(n=6$ of 46$)$ were $\mu / \kappa$ responsive, and the remaining $4 \%(n=2$ of 46$)$ did not respond to opioids. The proportion of the different opioid-responsive groups was not significantly different between randomly selected neurons from animals that had and had not received tracer injections $\left(p=0.3 ; \chi^{2}=2.6 ; \mathrm{df}=2\right)$. This suggests that spinal surgery and tracer injection had no effect on the opioid responses of RVM neurons.

\section{TPH immunoreactivity}

It is unclear what role raphe-spinal serotonergic neurons have in mediating the effects of opioids (see introductory remarks). We therefore examined whether the different groups of RVM neurons described above were immunoreactive for TPH, a marker of serotonergic neurons (Fig. 4).

Of the 73 retrogradely labeled RVM neurons from the first set of experiments, 60 biocytin-filled cells were recovered. Of these, $40 \%$ were immunoreactive for TPH (Fig. 5) $(n=24$ of 60$)$. The proportion of $\mu-, \kappa^{-}$, and $\mu / \kappa$-responsive groups differed between the TPH-positive and TPH-negative spinally projecting neurons (Fig. 6) $\left(p<0.001 ; \chi^{2}=15.8\right.$; df $\left.=2\right)$. Of the TPH-positive neurons, there were similar proportions of $\mu$-responsive $(33 \%$; $n=8$ of 24$), \kappa$-responsive $(25 \% ; n=6$ of 24$)$, and $\mu / \kappa$-responsive (33\%; $n=8$ of 24 ) neurons. Most of the TPH-negative neurons were $\mu$ responsive $(67 \% ; n=24$ of 36$)$, with smaller proportions of $\kappa$-responsive $(3 \% ; n=1$ of 36$)$ and $\mu / \kappa$-responsive $(19 \% ; n=$ 7 of 36) neurons. The other two TPH-positive and four TPHnegative neurons did not respond to either $\mu$ - or $\kappa$-opioid agonists. In addition, the proportion of TPH-immunoreactive neurons was similar in animals with more restricted spinal cord tracer injections ( $42 \% ; n=5$ of 12 ) and those with more extensive tracer injections $\left(40 \% ; n=12\right.$ of $30 ; p=0.9 ; \chi^{2}=0.01$; df $\left.=1\right)$.

Of the 52 randomly selected RVM neurons obtained in recordings from animals that had received tracer injections (see previous section), 37 biocytin-filled cells were recovered. Significantly fewer of the randomly selected neurons were TPH positive (Fig. 5) $(11 \% ; n=4$ of 37$)$, compared with the retrogradely labeled neurons $\left(p<0.005 ; \chi^{2}=9.5 ; \mathrm{df}=1\right)$. The proportion of $\mu-, \kappa^{-}$, and $\mu / \kappa$-responsive groups differed between the TPH-positive and TPH-negative neurons randomly selected from rats injected with tracer $\left(p=0.001 ; \chi^{2}=16.3\right.$; df $\left.=2\right)$. Of the TPH-negative randomly selected neurons, $79 \%(n=26$ of 33$)$ were $\mu$ responsive and $21 \%$ ( $n=7$ of 33 ) were $\mu / \kappa$ responsive. No $\kappa$-responsive neurons were found to be TPH negative. The TPH-positive randomly selected neurons were all identified post hoc as containing fluorescent microspheres and were either $\kappa$-responsive $(50 \%$; $n=2$ of 4 ) or $\mu / \kappa$-responsive $(50 \% ; n=2$ of 4 ) neurons.

Of the randomly selected RVM neurons that were recovered in recordings from animals that had not received tracer injections, $15 \%$ ( $n=7$ of 46$)$ were TPH positive. This proportion of 

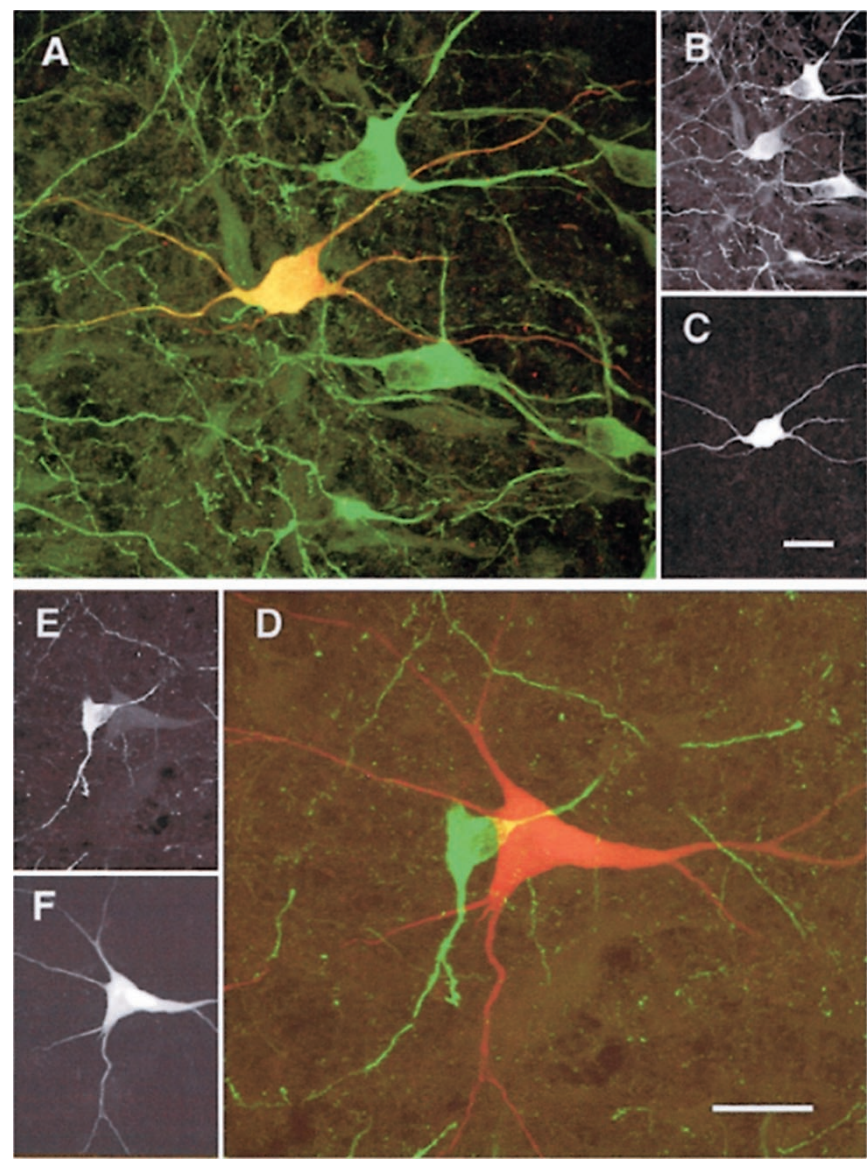

Figure 4. TPH immunoreactivity of electrophysiologically characterized RVM neurons. $A-C$, RVM neuron that expressed TPH-ir. This cell responded to $\mu$ - and $\kappa$-opioid receptor activation. $A$, Merged confocal images showing both the biocytin-filled cell (red) and TPH-ir (green). B, $C$, Separate images showing TPH-ir $(B)$ and biocytin $(C)$ labeling of the filled cell. $D-F, \mathrm{RVM}$ neuron that did not express TPH-ir. This cell responded to $\mu$-opioid receptor activation and had an action potential shape typical of $\mu$ responders. $D$, Merged confocal images showing both the biocytin-filled cell (red) and TPH-ir (green). Note the lack of double labeling. $E, F$, Separate images showing TPH-ir $(E)$ and biocytin $(F)$ labeling of the filled cell. Both neurons were identified as containing fluorescent microspheres before recording. Scale bars: $25 \mu \mathrm{m}$ (bar in $D$ applies to $A$ and $D$; bar in $C$ applies to $B, C, E$, and $F$ ).

TPH-positive neurons was similar to that obtained from randomly selected neurons from animals that had received tracer injections $\left(p=0.6 ; \chi^{2}=0.26 ; \mathrm{df}=1\right)$. Thus spinal cord exposure and tracer injection appear to have had no effect on the expression $\mathrm{TPH}$ immunoreactivity in RVM neurons.

In current-clamp recordings of action potentials from injected and noninjected animals, TPH-positive neurons had relatively long-duration action potentials (half width $=2.1 \pm 0.4 \mathrm{msec} ; n=$ 14) and always had slow afterhyperpolarizations. The TPHnegative cells had short-duration action potentials (half width $=$ $0.9 \pm 0.1 ; n=36$ ) and often had fast afterhyperpolarizations.

\section{Anatomical distribution of different RVM neuronal types}

The locations of recovered cells from which opioid responses and TPH immunoreactivity were assessed are shown in Figure 7.

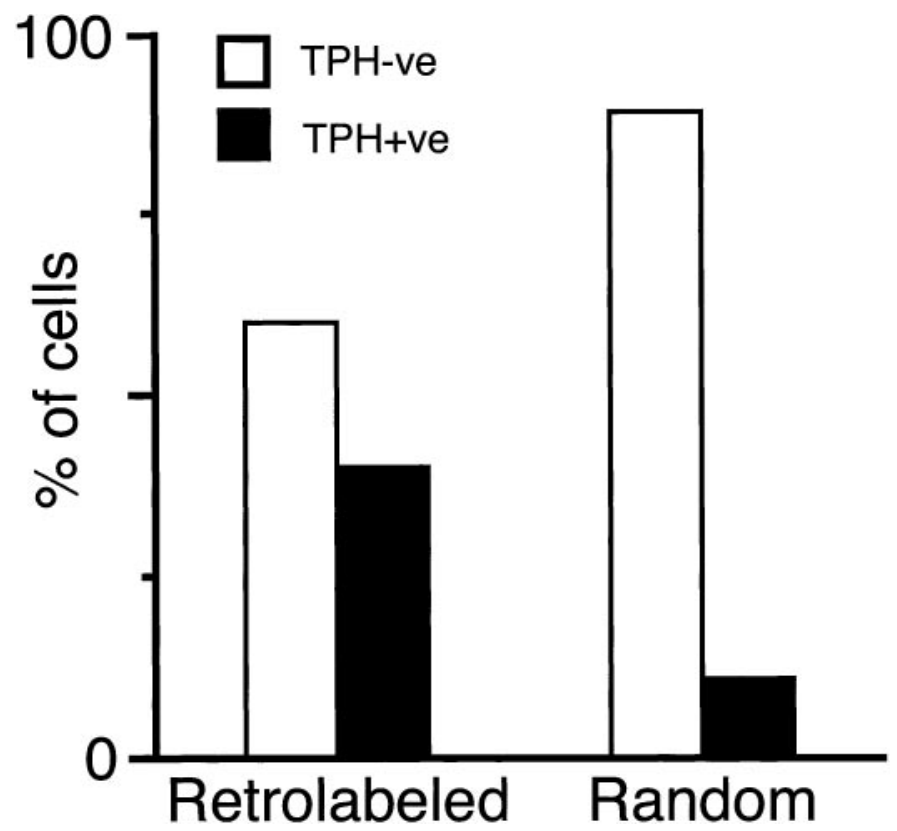

Figure 5. The proportion of TPH-immunoreactive neurons differs between spinally projecting and randomly selected RVM neurons. Bar charts display the percentage of TPH-positive neurons $(\mathrm{TPH}+v e$, filled bar) and TPH-negative neurons (TPH-ve, open bar) in recordings from retrogradely labeled neurons using fluorescence illumination (Retrolabeled) and from randomly sampled neurons with the fluorescence illumination off (Random). Both retrolabeled and random neurons are from animals that had received previous spinal injections of fluorescent microspheres. The proportion of TPH-positive neurons was higher for the retrogradely labeled neurons than for the randomly selected neurons $(p<0.005$; see Results $)$.

Most of the retrogradely labeled neurons or randomly selected neurons (from either injected and noninjected animals) were found throughout the rostrocaudal axis of the RVM. Most of the cells were concentrated in nucleus raphe magnus at the level of the superior olivary complex (76\%; $n=89$ of 117), with fewer neurons at the level of the facial nucleus (18\%; $n=21$ of 117). Both TPH-positive and TPH-negative cell types and $\mu-, \kappa_{-}$, and $\mu / \kappa$-responsive cell types were present at both levels of the RVM. However, there were insufficient numbers of each cell type to allow statistical comparison of their relative proportions at the two levels. A small percentage of the neurons were located rostral to the RVM ( $6 \% ; n=7$ of 117$)$.

\section{DISCUSSION}

The principal conclusions of this study are that spinally projecting serotonergic and nonserotonergic RVM cells are directly inhibited by $\mu$ - and $\kappa$-opioid receptor activation and that inhibition of these and other RVM neurons may mediate, at least in part, opioid analgesia. These findings indicate that spinally projecting populations of RVM neurons exist that are likely to modulate nociception and have not previously been sampled electrophysiologically. This suggests the need to redefine in vitro models and reexamine the pharmacological properties of RVM neurons in vivo. 


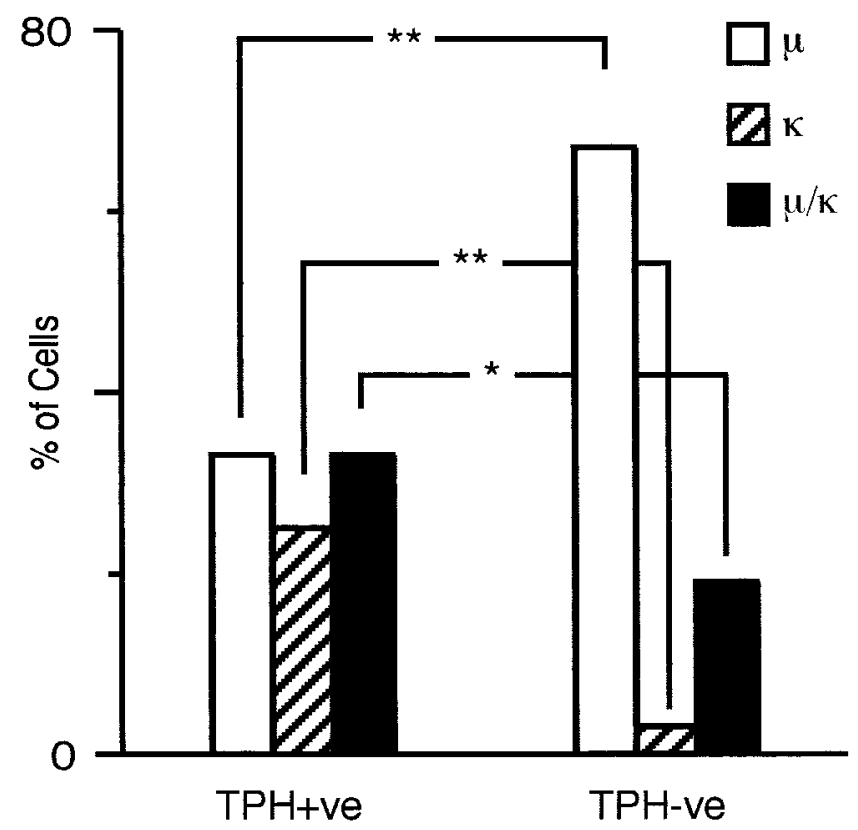

Figure 6. The proportion of opioid-responding subtypes differs between spinally projecting TPH-positive and TPH-negative RVM neurons. The bar chart displays the percentage of $\mu-, \kappa-, \mu / \kappa$-opioid-responding neurons in recordings of cells retrogradely labeled from the spinal cord that were identified as TPH positive $(T P H+v e)$ or TPH negative $(T P H-v e) .{ }^{* *} p<$ $0.0001 ; * p<0.005$.

\section{RVM spinally projecting neurons}

In the present study, a large proportion of the spinally projecting neurons were identified as serotonergic (40\%; on the basis of TPH immunoreactivity). This observation is consistent with previous anatomical and electrophysiological studies in adult animals (Wessendorf et al., 1981; Skagerberg and Bjorklund, 1985), and the presence of serotonergic neurons in neonates agrees with previous anatomical studies (Levitt and Moore, 1978; Wallace and Lauder, 1983; Petko and Stunya, 1987). Furthermore, both serotonergic and nonserotonergic spinally projecting RVM neurons were directly inhibited by $\mu$ opioids or $\kappa$ opioids, or both. This observation is consistent with anatomical experiments in adult animals which found that $\mu$ - and $\kappa$-opioid receptor mRNA and/or protein are expressed by serotonergic and nonserotonergic bulbospinal RVM neurons (Kalyuzhny et al., 1996; Kalyuzhny and Wessendorf, 1998, 1999; Wang and Wessendorf, 1999). The present observations support the hypothesis that some, but not all, spinally projecting serotonergic RVM neurons respond directly to opioids and suggests that the supraspinal circuitry necessary for opioid antinociception is present at an early age.

Of the spinally projecting serotonergic RVM neurons, $33 \%$ were $\mu$ responsive and $25 \%$ were $\kappa$ responsive; moreover, another $33 \%$ were responsive to both $\mu$ and $\kappa$ opioids. Thus it appears likely that bulbospinal serotonergic neurons play a direct role in mediating the effects of both $\mu$ - and $\kappa$-opioid agonists. These findings differ with previous in vitro neonatal animals studies in which serotonergic neurons were suggested to be primary cells, which are directly inhibited by $\kappa$ opioids but not $\mu$ opioids (Pan et al., 1990, 1993, 1997). It is unclear why previous studies of serotonergic neurons have not reported $\mu$-opioid responses, although this may be related to effects of anesthesia (Leung and Mason,
1995), to cancellation of direct inhibitory effects by indirect excitatory (disinhibitory) effects, to the fact that the spinal projections of the neurons were not examined in previous in vitro studies, or to a combination of the above factors.

The largest proportion of RVM neurons projecting to the spinal cord were nonserotonergic $(60 \%)$ and may in part have been GABAergic (Kalyuzhny and Wessendorf, 1998). These neurons were mostly $\mu$ - $(67 \%)$ or $\mu / \kappa$-opioid (19\%) responsive. Consistent with previous in vivo studies of $\mu$-opioid actions on nonserotonergic cells, the present data indicate that $\mu$-opioid responding spinally projecting nonserotonergic cells are heterogeneous. In these studies it was found that subpopulations of nonserotonergic cells may also express functional $\kappa$ receptors. On the basis of the in vivo actions of $\kappa$ opioids in RVM (Pan et al., 1997; Ackley et al., 2001), it appears possible that the $\mu$ - and $\mu / \kappa$-responsive nonserotonergic spinal projection neurons that we have identified represent populations of $\mathrm{ON}$ and OFF cells, respectively (Fig. 8). Thus we predict that nonserotonergic OFF cells projecting to the spinal cord will be directly inhibited by $\kappa$-opioid agonists in vivo.

The spinally projecting populations of RVM neurons are therefore heterogeneous with respect to opioid responsiveness and TPH immunoreactivity. In addition, these neurons differ in their action potential shape as reported previously (Zagon et al., 1997); however, the respective functions of these neuronal types, including opioid responding and nonresponding neurons, are not certain. At least in some cases, differential expression of opioid receptors is associated with axonal projection to different laminas of the spinal cord (Arvidsson et al., 1995). Recent studies have identified clear ON- and OFF-cell behavior in response to different noxious stimulation, or after inflammation, in cells characterized previously as NEUTRAL-cells (Ellrich et al., 2000; Miki et al., 2002). Such behavior might also be associated with the patterns of opioid responsiveness that we have identified in serotonergic neurons.

\section{Unlabeled RVM neurons}

In contrast to the spinally projecting neurons, few of the randomly selected RVM neurons were serotonergic (11\%), which is in agreement with previous anatomical observations (Potrebic et al., 1994). Most of these randomly selected neurons were $\mu$ - $(75 \%)$ or $\mu / \kappa$-opioid responsive ( $13 \%)$, and few were identified post hoc as retrogradely labeled. Most of these unlabeled neurons were $\mu$-opioid responsive (92\%), and none were serotonergic. These unlabeled neurons resemble the secondary cells identified in previous in vitro studies (Pan et al., 1990, 1993). Some of these unlabeled cells may have projected to sites that we regularly missed with our tracer injections, such as the deep ventral horn. However, their responses were significantly different from those identified as spinally projecting neurons, and it appears likely that at least some of those cells were $\mu$-opioid-responsive GABAergic interneurons that do not project to the spinal cord (Fig. 8).

\section{Pronociceptive RVM circuitry}

In the present study, a significant proportion of spinally projecting RVM neurons were directly inhibited by $\mu$-opioid agonists. As mentioned above, the antinociceptive role of the RVM in opiate analgesia has been proposed to be attributable to excitation (via $\mu$-opioid disinhibition) of bulbospinal antinociceptive neurons. It 


\section{A. Retrolabeled}

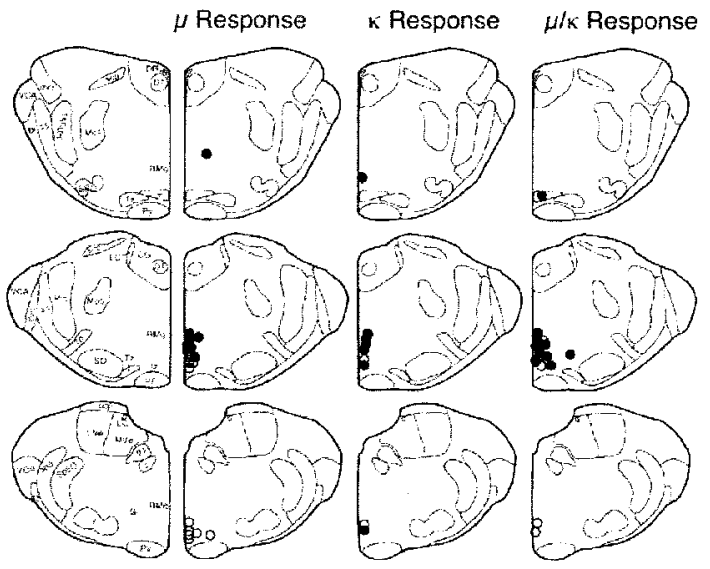

\section{B. Random (injected)}

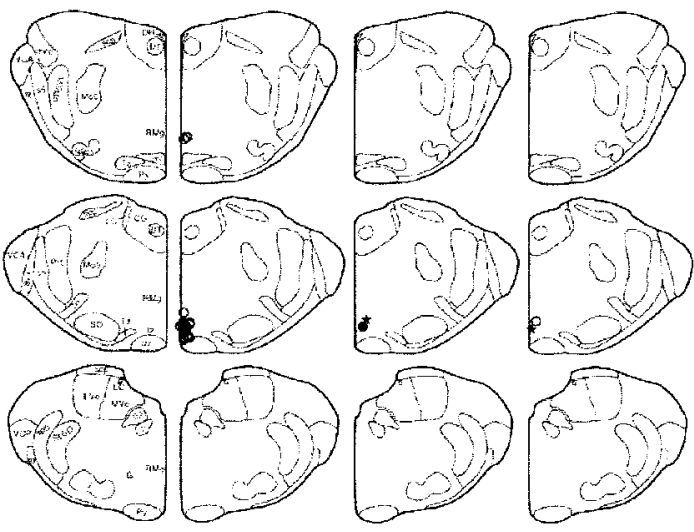

C. Random (non-injected)

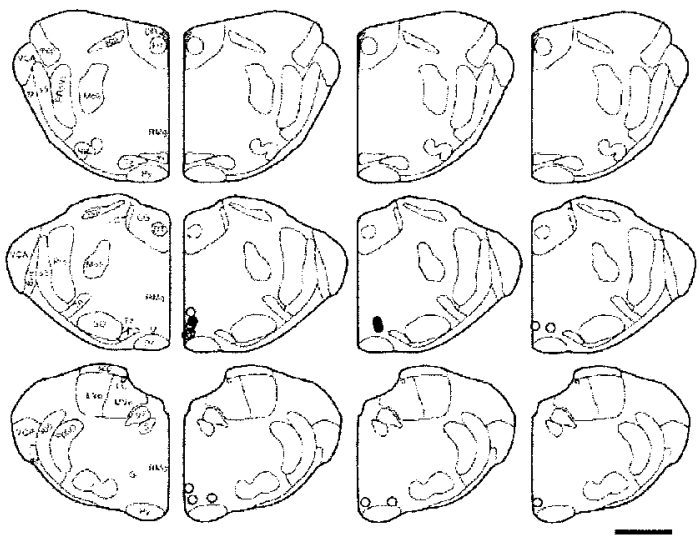

Figure 7. Distribution of characterized RVM cells. Biocytin-filled cells were categorized by their responses to selective $\mu$ - and $\kappa$-opioid agonists and by the presence of TPH-ir (serotonergic). These cells were mapped onto drawings of caudal, intermediate, and rostral RVM (based on the presence of the seventh cranial nerve, the inferior olive, or the superior olive). $A$, Retrogradely labeled neurons that were first identified as containing fluorescent beads after spinal injections of fluorescent microspheres (Retrolabeled). B, Randomly selected cells in animals that had been injected spinally with fluorescent microspheres [Random (injected)]. $C$, Randomly selected cells in animals that had not received spinal tracer injections [Random (non-injected)]. A, C, Filled circles indicate TPH positive; open circles indicate TPH negative. B, Filled symbols indicate TPH positive; open symbols indicate TPH negative; stars indicate cells found

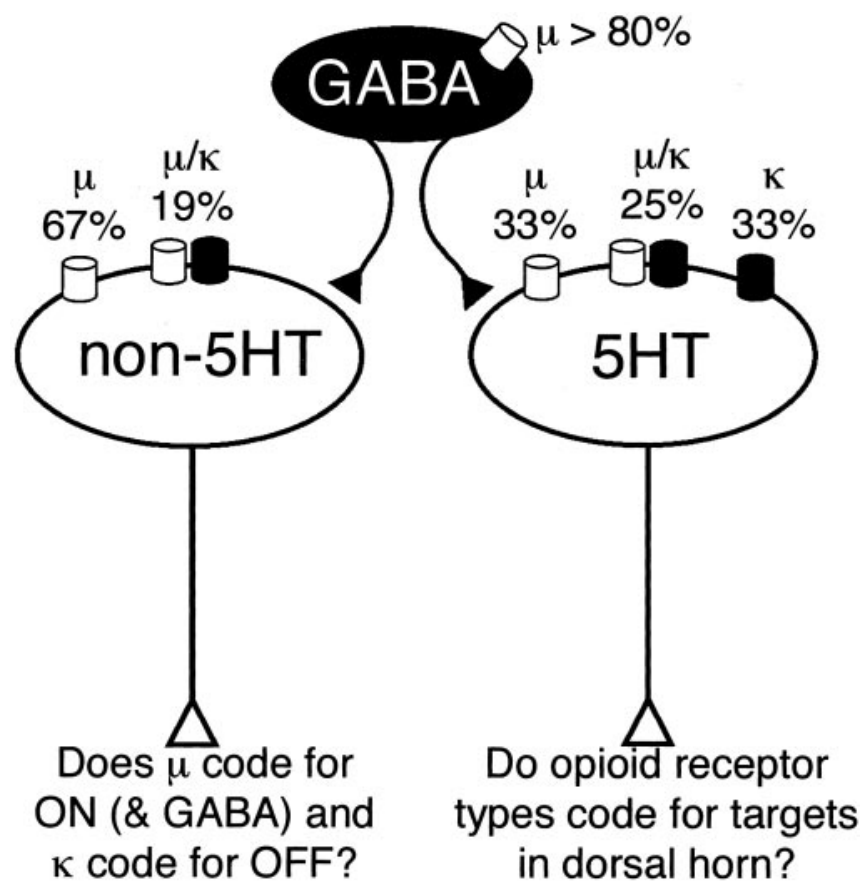

Figure 8. Proposed model of RVM opioid actions. Schematic diagram illustrates the opioid receptor subtypes on the different populations of RVM neurons. Of the RVM neurons that project to the spinal cord dorsal horn, $40 \%$ are serotonergic. These serotonergic projection neurons $(5 H T)$ have $\mu$-, $\kappa^{-}$and $\mu / \kappa$-opioid-responding subtypes. The functional role of each of these neuronal subtypes is unknown, and they might have distinct spinal targets. The nonserotonergic projection neurons (non-5HT) are composed of $\mu$ - and $\mu / \kappa$-opioid-responding subtypes and may code for ON- versus OFF-neurons, respectively. RVM neurons that were not retrogradely labeled were nonserotonergic and mostly $\mu$-opioid responsive. Our model predicts that some of these nonretrogradely labeled neurons are GABAergic interneurons $(G A B A)$ that might also correspond to a population of $\mathrm{ON}$-cells. In addition, a small population of projection neurons $(\sim 10 \%)$ did not respond to opioids. These could correspond to either NEUTRAL-cells or OFF-cells.

is unclear what functional role is played at the spinal level by the bulbospinal $\mu$-responsive neurons that we detected, but it is possible that these cells inhibit nociception. If so, it would suggest that the direct inhibitory effects of $\mu$-opioid agonists on these cells (effects that would promote, rather than inhibit, nociception) can be overwhelmed by the indirect disinhibitory effects that opioids reportedly exert.

\section{$\leftarrow$}

post hoc to be retrogradely labeled from the spinal cord; circles indicate cells that were not retrogradely labeled. Scale bar, $1 \mathrm{~mm}$. 6, Abducens nucleus; 7 , facial nucleus; $7 n$, facial nerve; $8 v n$, vestibular root vestibulocochlear nerve; $C G$, central gray; $D R$, dorsal raphe nucleus; $D T$, dorsal tegmental nucleus; $g 7$, genu of the facial nerve; $G i$, gigantocellular reticular nucleus; $L C$, locus coeruleus; $L v e$, lateral vestibular nucleus; $m c p$, middle cerebellar peduncle; $m l$, medial lemniscus; Mo5, motor trigeminal nucleus; $M v e$, medial vestibular nucleus; $P R 5 V L$, principal sensory trigeminal nucleus, ventrolateral part; $\operatorname{Pr} 5$, principal sensory trigeminal nucleus; py, pyramidal tract; $R M g$, raphe magnus nucleus; $s 5$, sensory root of the trigeminal nerve; $s c p$, superior cerebellar peduncle; $S O$, Superior olive; $S p 5 O$, spinal trigeminal nucleus, oral part; $S P O$, superior paraolivary nucleus; $t z$, trapezoid body; $T z$, nucleus of the trapezoid body; $V C A$, ventral cochlear nucleus, anterior part; $V C P$, ventral cochlear nucleus, posterior part. 
An alternative explanation is that these $\mu$-responsive spinally projecting neurons facilitate nociception. These neurons might represent the cells that mediate nociceptive facilitation produced by stimulation of the RVM (Zhuo and Gebhart, 1990, 1992, 1997). This nociceptive facilitation has been reported to be reduced by spinal serotonergic antagonists, suggesting that it is mediated by bulbospinal serotonergic neurons (Zhuo and Gebhart, 1991), although other neurotransmitters may also be involved in these circuits (Urban et al., 1996; Kovelowski et al., 2000). Such a pronociceptive pathway has been proposed to mediate the increased nociception observed in various chronic pain states. For example, activation of spinally projecting cells facilitates both morphine tolerance and the paradoxical condition of opioid-induced hyperalgesia (Vanderah et al., 2001), and the activity of ON-cells is enhanced during some of these phenomena (Bederson et al., 1990). Consistent with these findings, opiate tolerance and withdrawal can be decreased by microinjection of lidocaine into the RVM (Kaplan and Fields, 1991; Vanderah et al., 2001). Similarly, the allodynia associated with peripheral neuropathy is also reduced by blockade of the RVM (Kovelowski et al., 2000) and by selective lesioning of $\mu$-opioid receptor expressing RVM cells (Porreca et al., 2001). Thus the actions of opioid analgesics may be caused not only by disinhibition of antinociceptive bulbospinal neurons but also by inhibition of opioid-responsive RVM bulbospinal neurons that facilitate nociception.

\section{REFERENCES}

Ackley MA, Hurley RW, Virnich DE, Hammond DL (2001) A cellular mechanism for the antinociceptive effect of a kappa opioid receptor agonist. Pain 91:377-388.

Arvidsson U, Dado RJ, Riedl M, Lee JH, Law PY, Loh HH, Elde R, Wessendorf MW (1995) $\delta$-Opioid receptor immunoreactivity: distribution in brainstem and spinal cord, and relationship to biogenic amines and enkephalin. J Neurosci 15:1215-1235.

Azami J, Llewelyn MB, Roberts MH (1982) The contribution of nucleus reticularis paragigantocellularis and nucleus raphe magnus to the analgesia produced by systemically administered morphine, investigated with the microinjection technique. Pain 12:229-246.

Bederson JB, Fields HL, Barbaro NM (1990) Hyperalgesia during naloxone-precipitated withdrawal from morphine is associated with increased on-cell activity in the rostral ventromedial medulla. Somatosens Mot Res 7:185-203.

Christie MJ (1998) Do medullary serotonergic neurons tonically modulate nociceptive transmission. Pain Forum 7:155-158.

Ellrich J, Ulucan C, Schnell C (2000) Are "neutral cells" in the rostral ventro-medial medulla subtypes of on- and off-cells? Neurosci Res 38:419-423.

Fields HL, Basbaum AI (1999) Central nervous system mechanisms of pain modulation. In: Textbook of pain, Ed 4 (Wall PD, Melzack R, eds), pp 309-329. London: Churchill Livingston.

Fields HL, Barbaro NM, Heinricher MM (1988) Brain stem neuronal circuitry underlying the antinociceptive action of opiates. Prog Brain Res 77:245-257.

Fields HL, Heinricher MM, Mason P (1991) Neurotransmitters in nociceptive modulatory circuits. Annu Rev Neurosci 14:219-245.

Fields HL, Malick A, Burstein R (1995) Dorsal horn projection targets of $\mathrm{ON}$ and $\mathrm{OFF}$ cells in the rostral ventromedial medulla. J Neurophysiol 74:1742-1759.

Gao K, Kim YH, Mason P (1997) Serotonergic pontomedullary neurons are not activated by antinociceptive stimulation in the periaqueductal gray. J Neurosci 17:3285-3292.

Gao K, Chen DO, Genzen JR, Mason P (1998) Activation of serotonergic neurons in the raphe magnus is not necessary for morphine analgesia. J Neurosci 18:1860-1868.

Hammond DL, Yaksh TL (1984) Antagonism of stimulation-produced antinociception by intrathecal administration of methysergide or phentolamine. Brain Res 298:329-337.

Heinricher MM, Morgan MM, Fields HL (1992) Direct and indirect actions of morphine on medullary neurons that modulate nociception. Neuroscience 48:533-543.

Heinricher MM, Morgan MM, Tortorici V, Fields HL (1994) Disinhibition of off-cells and antinociception produced by an opioid action within the rostral ventromedial medulla. Neuroscience 63: 279-288.

Heinricher MM, McGaraughty S, Farr DA (1999) The role of excitatory amino acid transmission within the rostral ventromedial medulla in the antinociceptive actions of systemically administered morphine. Pain 81:57-65.

Huang LYM (1998) Tonic release of serotonin. A mechanism for antinociception? Pain Forum 7:151-154.

Kalyuzhny AE, Wessendorf MW (1998) Relationship of mu- and deltaopioid receptors to GABAergic neurons in the central nervous system, including antinociceptive brainstem circuits. J Comp Neurol 392:528-547.

Kalyuzhny AE, Wessendorf MW (1999) Serotonergic and GABAergic neurons in the medial rostral ventral medulla express kappa-opioid receptor immunoreactivity. Neuroscience 90:229-234.

Kalyuzhny AE, Arvidsson U, Wu W, Wessendorf MW (1996) muOpioid and delta-opioid receptors are expressed in brainstem antinociceptive circuits: studies using immunocytochemistry and retrograde tract-tracing. J Neurosci 16:6490-6503.

Kaplan H, Fields HL (1991) Hyperalgesia during acute opioid abstinence: evidence for a nociceptive facilitating function of the rostral ventromedial medulla. J Neurosci 11:1433-1439.

Kovelowski CJ, Ossipov MH, Sun H, Lai J, Malan TP, Porreca F (2000) Supraspinal cholecystokinin may drive tonic descending facilitation mechanisms to maintain neuropathic pain in the rat. Pain 87: 265-273.

Leung CG, Mason P (1995) Effects of isoflurane concentration on the activity of pontomedullary raphe and medial reticular neurons in the rat. Brain Res 699:71-82.

Levitt P, Moore RY (1978) Developmental organization of raphe serotonin neuron groups in the rat. Anat Embryol 154:241-251.

Mason P, Gao K (1998) Raphe magnus serotonergic neurons tonically modulate nociceptive transmission. Pain Forum 7:143-150.

Miki K, Zhou QQ, Guo W, Guan Y, Terayama R, Dubner R, Ren K (2002) Changes in gene expression and neuronal phenotype in brain stem pain modulatory circuitry after inflammation. J Neurophysiol $87: 750-760$.

Pan ZZ, Williams JT, Osborne PB (1990) Opioid actions on single nucleus raphe magnus neurons from rat and guinea-pig in vitro. J Physiol (Lond) 427:519-532.

Pan ZZ, Wessendorf MW, Williams JT (1993) Modulation by serotonin of the neurons in rat nucleus raphe magnus in vitro. Neuroscience 54:421-429.

Pan ZZ, Tershner SA, Fields HL (1997) Cellular mechanism for antianalgesic action of agonists of the kappa-opioid receptor. Nature 389:382-385.

Petko M, Stunya E (1987) Ontogenesis of serotoninergic nuclei in the rat stem. Folia Histochem Cytobiol 25:143-148.

Porreca F, Burgess SE, Gardell LR, Vanderah TW, Malan TP, Ossipov MH, Lappi DA, Lai J (2001) Inhibition of neuropathic pain by selective ablation of brainstem medullary cells expressing the $\mu$-opioid receptor. J Neurosci 21:5281-5288.

Potrebic SB, Fields HL, Mason P (1994) Serotonin immunoreactivity is contained in one physiological cell class in the rat rostral ventromedial medulla. J Neurosci 14:1655-1665.

Skagerberg G, Bjorklund A (1985) Topographic principles in the spinal projections of serotonergic and non-serotonergic brainstem neurons in the rat. Neuroscience 15:445-480.

Urban MO, Smith DJ, Gebhart GF (1996) Involvement of spinal cholecystokininB receptors in mediating neurotensin hyperalgesia from the medullary nucleus raphe magnus in the rat. J Pharmacol Exp Ther 278:90-96.

Vanderah TW, Suenaga NM, Ossipov MH, Malan Jr TP, Lai J, Porreca F (2001) Tonic descending facilitation from the rostral ventromedial medulla mediates opioid-induced abnormal pain and antinociceptive tolerance. J Neurosci 21:279-286.

Vanegas H, Barbaro NM, Fields HL (1984) Tail-flick related activity in medullospinal neurons. Brain Res 321:135-141.

Wallace JA, Lauder JM (1983) Development of the serotonergic system in the rat embryo: an immunocytochemical study. Brain Res Bull 10:459-479.

Wang H, Wessendorf MW (1999) Mu- and delta-opioid receptor mRNAs are expressed in spinally projecting serotonergic and nonseroton- 
ergic neurons of the rostral ventromedial medulla. J Comp Neurol 404:183-196.

Wessendorf MW (1998) The role of serotonergic neurons in nucleus raphe magnus in opioid antinociception. Pain Forum 7:159-162.

Wessendorf MW, Proudfit HK, Anderson EG (1981) The identification of serotonergic neurons in the nucleus raphe magnus by conduction velocity. Brain Res 214:168-173.

Yaksh TL, Al-Rodhan NR, Jensen TS (1988) Sites of action of opiates in production of analgesia. Prog Brain Res 77:371-394.

Zagon A, Meng XW, Fields HL (1997) Intrinsic membrane characteristics distinguish two subsets of nociceptive modulatory neurons in rat rvm. J Neurophysiol 78:2848-2858.

Zhuo M, Gebhart GF (1990) Characterization of descending inhibition and facilitation from the nuclei reticularis gigantocellularis and gigantocellularis pars alpha in the rat. Pain 42:337-350.

Zhuo M, Gebhart GF (1991) Spinal serotonin receptors mediate descending facilitation of a nociceptive reflex from the nuclei reticularis gigantocellularis and gigantocellularis pars alpha in the rat. Brain Res $550: 35-48$

Zhuo M, Gebhart GF (1992) Characterization of descending facilitation and inhibition of spinal nociceptive transmission from the nuclei reticularis gigantocellularis and gigantocellularis pars alpha in the rat. J Neurophysiol 67:1599-1614.

Zhuo M, Gebhart GF (1997) Biphasic modulation of spinal nociceptive transmission from the medullary raphe nuclei in the rat. J Neurophysiol 78:746-758. 